


\title{
Social
}

\section{IRAQI EFL STUDENTS' AWARENESS OF THE PRONUNCIATION OF MORPHOPHONEMIC CHANGED WORDS AT A COLLEGE LEVEL}

\author{
Faris Kadhim Te'ama Al-Atabi (Ph.D) ${ }^{1}$, Hashim Aliwy Mohammed Alhusseini (Ph.D) *2 \\ $1,{ }^{* 2}$ Department of English, College of Education, University of Wasit, Iraq
}

\begin{abstract}
This study is concerned with the morphophonemic changes as one of the most common processes in the English derivation and as a problematic area for English language learners. The study aims at investigating Iraqi college students' awareness in pronouncing the morphophonemic changes of words. To achieve this aim, the study adopts a diagnostic test of two questions. It was found that Iraqi university learners are unaware of the pronunciation of morphophonemic changes as the highest rate of their incorrect responses and the students are much unawareness at the production level than the recognition level. In the light of the results, certain recommendations and suggestions have been put for further studies.
\end{abstract}

Keywords: Morphophonemic Changes; Pronunciation; Production Level; Recognition Level.

Cite This Article: Faris Kadhim Te'ama Al-Atabi, and Hashim Aliwy Mohammed Alhusseini (2018). "IRAQI EFL STUDENTS' AWARENESS OF THE PRONUNCIATION OF MORPHOPHONEMIC CHANGED WORDS AT A COLLEGE LEVEL.” International Journal of Research - Granthaalayah, 6(8), 69-83. 10.29121/granthaalayah.v6.i8.2018.1263.

\section{Introduction}

To learn any foreign language, learners must master its main areas, i.e., phonetics or phonology, morphology, grammar (syntax) and vocabulary (semantics), and all its skills, i.e., listening, speaking, reading and writing. Thus, any sort of weakness during practicing any language, the learner commits errors especially in phonology, i.e., when the speaker utters or pronounces the word in another way that may be misunderstood by the hearer. As an essential activity in the target language as the pronunciation, students must acquire all aspects of its components. Weeren and Theunissen (1987, p. 109) point out that there are good reasons for not neglecting pronunciation skill. They state that a good pronunciation makes one or the speaker understood; whereas a deviant pronunciation makes the message or a speaker is distinguished as a stranger or "as a nonnative abroad"; and the good "pronunciation is quite attractive as a learning objective".

Undergraduate students at college of education, whose major job is to teach English, still face difficulty in recognizing and pronouncing words after adding certain affixes, i.e., morphophonemic 
changes (Mphchs henceforth). After observing the students for a long period of learning English language, it was found that they lack the ability to recognize and pronounce the Mphchs.

Having such inability in the pronunciation of the Mphchs will lead to inefficient and unqualified teachers that they would not be a good modal, and this in turn will affect the achievements of the pupils in this area of language learning. Al-Hamash and Younis (1985, p. 20) state that:

If the teacher lacks efficiency in the language skills, he is a poor modal. The teacher, then, is the cornerstone of the process of language learning and teaching. Being so important, the teacher, therefore, ought to have a native like in the foreign language he is teaching.

One of the reasons behind the students' failure in recognizing and pronouncing the Mphchs may be attributed to the lack entries of Mphchs in most of the English language dictionaries. Previous studies that surveyed the area of morphophonemics and morphophonology (or morphonology) ignore the learners' role in this regard. Therefore, the present study is intended to tackle the Iraqi EFL students' awareness of the pronunciation of Mphchs within the context of words. The paper presents a survey of Mphchs related to the pronunciation and provides pedagogical implications for teaching pronunciation. The paper also has the practical value for the dictionaries designers to design a new dictionary contains the Mphchs, since this feature is absolutely, if not partially, hidden in many dictionaries.

The study aims to highlight the importance of Mphchs and investigate Iraqi EFL college students' awareness of the pronunciation of Mphchs. The study is limited to deal with Morphophonemic changes; the change that takes place in the pronunciation of the original (stem) after adding certain suffixes. It also limited to Fourth stage of EFL College students at University of Wasit/ College of Education/ English Department.

The researchers adopt the following procedures to accomplish this study:

1) Presenting a due account regarding Mphchs;

2) Choosing a sample of students;

3) Designing a recognition and production test in order to achieve the aims of the study and to verify the hypothesis posed; and

4) Analyzing and discussing the results obtained.

\section{Literature Review}

Right from the beginning, the morphophonemic study is concerned with morpheme as well as phonology. It can be considered as a separate field of grammar, since it attempts to classify, analyze, and show how the morphemes operate in the phonological level. In this regard, Crystal (2008, p. 315) states that morphophonemics is an important branch of linguistics that can be "seen as a separate level of linguistic structure intermediate between grammar and phonology".

Generally, one can say that morphophonemics studies morphemes from the point of view of their phonological shapes. Morphophonemics thus enumerates, analyzes, and classifies such phonological shapes with the purpose of providing an understanding of how morphemes operate at the level of phonology. Morphemes are abstract units of grammatical analysis which appear 
in various phonological shapes (Thakur, 1997). Based on this view, Lyons (1968, p. 116) describes morphophonemics as "a section of linguistic description intermediate between grammar and phonology".

\subsection{Morphophonemic Changes}

As mentioned earlier that one of the morphophonemics tasks is to investigate how the morphemes operate in the phonological level. This indicates that certain changes may happen when there is an interrelationship between a phoneme and morpheme. In this respect, Kroeger (2005, p. 292) states that "morphophonemic change involves not replacing but changing the phonological shape of a morpheme. A morphophonemic process can be described as a change in one or more phonemes triggered by the phonological properties of a neighboring morpheme".

Stagberg (1981, p. 135) points out that changes in the phonemic form of certain allomorphs such as the plural suffix (-es or $-s$ ) as they appear in different forms of a word are called morphophonemic changes. Principally, the present study is only concerned with the changes that take place in the pronunciation of the stem after adding certain suffixes. This can be clearly exemplified in the plural English suffix allomorph (-es or - s) as in: house $+\mathbf{s} / \mathbf{h a u z i z} /$; Calf $+\mathbf{s}$ /kavz/; Mouth + s /mauðz. Some nouns ending in /f, $\Theta /$ do not make a Mphch, like chiefs; others have two forms of plural, like /yuӨs/ or /yuðz/ (Stagberg, 1981, p. 135).

\subsection{Bloomfield's Process of Morphophonemics}

Leonard Bloomfield captured a new description of the process of morphophonemic representations. Fudge (1973, p. 91) states that Bloomfield's procedures had been declared as follow:

Whenever possible take one allomorph (alternant in his terminology) as a basic, and derive the other from it by rule. So in knife, he takes the phonemic shape /knaif/ as the basic alternant or undertaking form, and specifies as a set of procedures for obtaining the correct alternant. Thus, the 'peculiarity' of the plurals of knife, mouth, hou-se can be described by saying that the final $\{f, \Theta$, s \} underlying singular is replaced by $/ \mathrm{v}, \mathrm{z}, \mathrm{\partial} /$ before the bound form $\{=$ plural suffix $\}$ is added.

This means that the correct description here is a series of steps or procedures in which two steps are applied to /naif/. The first one is to change the voiceless final consonant into the voiced one; whereas the second is to attach the appropriate alternant of the plural suffix. Fudge (1973, p. 95) shows that "Bloomfield introduces two fundamentally important notions: a- mutation rules (rules that change one thing into another, or replace one with another); and b- process of rule order: processes, at least sometimes must be applied in particular sequences to get the correct results.

It is worthy to mention that adding affixation to a word may cause three simultaneous levels of Mphchs, i.e., levels of morphology, syntax and semantics (Thakur, 1999, p. 51). Thus, the suffix (-ature) when added to the verb (sign) may face three Mphchs at three levels. At the level of morphology, the suffix (-ature) is added to the base or stem word (sign) to produce signature; syntactically, the verb (sign) is changed into a noun; whereas semantically, the meaning of an action produced by the verb (sign) is changed into another meaning that refers to a person's name 
indicated by the noun (signature). Moreover, the change can mainly be noticed at the level of phonology in addition to the above three levels, as in the above examples.

\section{Methodology}

This section attempts to explain the procedures that have been used in this study regarding the participants, the instrument (test), and the data or material selection of the test. It is also concerned with the discussion of the test virtues in term of reliability and validity through the use of the statistical means. Finally, this section describes the pilot and the main administration of the test along with the scoring scheme which has been adopted.

\subsection{Sample of the Study}

The sample of this study consists of 140 students chosen randomly from the $4^{\text {th }}$ grade college students at the English department during the academic year (2016-2017). Repeaters and teachers have been excluded to avoid previous experiences that may affect the study results. The choice of the $4^{\text {th }}$ grade students than any other grades is attributed to some factors. Firstly, they are most advanced and in the ultimate year of a study; second, they have studied phonetics, phonology and morphology in the previous years. The topics of the test under investigation have been taught to them in the second and third grades of the study at university. The number of the participants is 140 students taken from three sections. They represent $(80 \%)$ of the total number of the students in this stage (see table 1).

\subsection{Instrument}

To achieve the aims of the study, a test has been designed in a way that tests the subjects at both levels: recognition and production. The test consists of two questions: the first is designed to measure the subjects' responses at the recognition level; while the second question is formed to measure the subjects' responses at the production level. Each question includes 25 items. Multiple choice question which consists of 25 items is set to test the learners at the recognition level.

This test is intended to measure the subjects' ability to choose the correct pronunciation (sounds) of the Mphchs (see appendix 1). The second question which also includes 25 items is a gap filling test in a form of a table. In this respect, Van Else (1984, p. 323) claims that "gap filling items are more reliable, more valid, and preferred by many teachers". The Testees are required to supply a correct form of the appropriate transcription of the words (before and after) adding a certain suffix (see appendix 2).

\subsection{Validity and Reliability of the Test}

Validity is the appropriateness of a given test or any of its components parts as a measure of what it is supposed to measure (Alderson, Clapham, \& Wall, 1995, p. 170). For Bell (1981) and Davies (1999), validity is concerned with the truth of the test and its relations to what it is intended to test. To achieve the test surface credibility or public acceptability, the present test has been exposed to some administrators who have shown their approval of the test as a whole (see appendices $3 \& 4$ ). 
Content validity depends on the analysis of the language being tested and the objectives of a particular course (Heaton, 1988, p. 160). Thus, the items of the present test are assumed to be valid as they are constructed to satisfy the items of the test.

Furthermore, the test has been submitted to a jury of experts in order to assess its face and content validity. The jury has judged the test as being valid to measure the purpose for which it is designed and offered some suggestions which have been taken into consideration (see appendix 4).

Accordingly, certain instructors have been modified, whereas some items have been replaced by others. On the other hand, reliability is the means which seeks for the accuracy of scoring and accuracy of administration procedures of the test (Gronlud, 1976). Weir (1993) and Stiggins (1999) state that reliability refers to the consistency of assessment scores and it shows the statistical methods used to establish consistency of students' performance within a given test or a cross more than one test. A test is reliable if its scores remain relatively stable from one administration to another (Harris, 1969). To ensure a reliable test, a definite scoring scheme has been used.

It is worthy to mention that the instructions of the test were clearly explained and the subjects were encouraged to answer the question of the test. Heaton (1988) mentions that there are different methods for estimating the reliability of a test such as test-retest, two equivalent forms, split-half, and Kurder-Richardson method. The method adopted to estimate the reliability of the present test is Kurder-Richardson in which the following formula has been taken into consideration:

$\mathrm{R}=\mathrm{N} / \mathrm{N} 1(1-(\mathrm{N}-\mathrm{m}) / \mathrm{Nx} 2)$

R: stands for "reliability"

$\mathrm{N}$ : stands for "the number of the items in the test"

m: stands for "the mean of the test scores"

$\mathrm{X}$ : stands for "the standard deviation of the test scores"

The computation of this formula has yielded that the reliability coefficient of the present test is (o.9) which is a highly positive correlation.

\subsection{Material Selection}

The whole sample has been exposed to the same test in "Mphchs" whose material is taken from the morphological and phonological, and grammatical books such as "An Introductory English Grammar" (1981) by N. Stageberg, in addition to other books mentioned in section two. Moreover, the selection of the items of the test and its questions have been approved by a jury of experienced university lecturers. List of the names of the jury members arranged according to their academic ranks (See appendix 4). 


\subsection{Pilot Administration}

The pilot test has been carried out immediately after the construction of the test. The aim behind the administrations of the pilot test is to specify the time required for the main test, to see whether the items of the test are clear to the subjects, to check which of them needs modifications, and to analyze the items to determine their effectiveness in terms of item difficulty and discrimination power of the item. A pilot test is applied on the $5^{\text {th }}$ of February 2016 on twenty subjects chosen randomly from the fourth year students in the department of English, College of Education/ University of Wasit. Those subjects have been excluded from the main test. The results of the pilot test had indicated that the time required to answer the whole items of the test was one hour. All the results obtained from the pilot administration of this test had been incorporated to the final version of the test.

\subsection{Item Analysis}

According to Davies (1999, p. 192), item analysis is "a means of estimating how much information each single item in a test contributes to the information provided by the test as a whole ". Baker (1989) states that item analysis is another technique which can be used with performance-reference test through the unidimensional trait assumptions underlying their use. Item analysis is the systematic evaluation of the effectiveness of the individual items of a test. The aim of such analysis is to examine the test items of ease of difficulty and to discriminate between good and weak students (Brown, 1996). The difficulty level or (facility value) of each item is indicated by the percentage of the students who get the item right (Gronlund, 1976). Khodaday (1999) defines item difficulty as "the proportion of test takers who selected the keyed responses of a given multiple choice item". The following formula is used to find out the level of difficulty for each item in the tests:

\section{$\mathbf{F v}=\mathbf{N}$ correct $/ \mathbf{N}$ total}

This formula can be illustrated as follow:

Fv: stands for "facility value"

N correct: stands for "number of student answering correctly"

$\mathrm{N}$ total: stands for "the total number of the students taking the test" (Brown, 1996, p. 65).

After applying this formula to the results of the test, it has been found that the item difficulty ranges between 0.12 to 0.80 (see Table 2 below). In this respect, Bloom, Madaus \& Hastings (1981) point out that a good spread of results can be obtained if the items vary in difficulty from 0.20 to 0.80 . Therefore, the item difficulty of the present test is satisfactory. On the other hand, the following formula has been used to find out the item discrimination power:

\section{$\mathrm{DP}=\mathrm{RU}-\mathrm{RL} / \mathbf{1} / \mathbf{2 N}$,}

This formula can be illustrated as follows: 
DP: stands for "discrimination power"

RU: stands for "the number of the students in the upper group who got $\mathrm{c}$

RL: stands for "the number of the students in the lower group who got the item correct"

$\mathrm{N}$ : stands for "the total number of the testees included in the item analysis" (Brown, 1996, p. 65).

After calculation, it has been found that the discrimination power is between 0.20 and 0.80 (see Table 2). In this respect, Ahman and Glock (1975) assert that a good result can be obtained if the items vary in their discrimination power (0.20 and above). Accordingly, Ebel (1972, p. 359) admits that "good classroom test items have indices of discrimination of (0.30 or more)", see also Ferguson (1966, p. 167) and Larson (1982, p. 221).

\subsection{Final Administration}

The final form of the test has been administrated on the $15^{\text {th }}$ of February during the academic year 2016. The time allowed for answering the test is one hour. The instructions for each question are given to the subjects. They have been instructed to answer on the same sheets to save time and effort. They are asked not to write their names on the test sheets so as to avoid embarrassment. The process of marking the test has been done by the researchers using the scoring scheme presented in the following section.

\subsection{Scoring Scheme}

The scoring scheme is an important device to test the objectivity and reliability of the test. The test has been scored out of 50. It contains two questions including 50 items. Each question includes 25 items. The scores have been distributed in such a way to give one score (mark) for a correct answer and zero score for the incorrect one. The items that are left by the subjects with no answer are considered to be incorrect responses and are given a zero score, since the researchers predicted that the subjects have failed to give any answer.

\section{Results Discussions}

This section is to describe the set of the procedures followed in analyzing and discussing the data to arrive at certain concluding remarks. Thus, it starts with the analysis of the selected data to find out if the Iraqi EFL university learners are aware or not in the pronunciation of Mphchs. Finally, this section attempts to provide a presentation and discussion of the results with reference to the aims and hypothesis of the study.

\subsection{Data Analysis}

This section presents the general results of the test with the tables and statistical means. It also analyzes the performance of the subjects at the recognition and the production levels. The analysis of data is of great importance since it provides the basis upon which the hypothesis mentioned is either verified or refuted. 


\section{1) Frequency and Percentage of the Subjects' Performance in the pronunciation of morphophonemic changed words in the First Question}

The first question is used to measure the subjects' performance at the production level. Table 3 shows the frequency and the percentage of the subjects' performance on each item in this question:

It is concluded from Table (3) the following:

- The total number and the percentage of the correct responses are $(999,33.3)$, respectively (see appendix 5).

- The total number and the incorrect responses (including avoided items) are (2001, 66.7), respectively (see appendix 5).

- It can be concluded from the results presented in the table above that most of the subjects are unaware in their pronunciation of Mphchs since the total number of their incorrect responses outweighs that of their correct ones.

\section{2) Frequency and Percentage of the Subjects' Performance in Pronouncing Mphchs in the Second Question.}

The question is designed to measure the subjects' ability to recognize Mphchs, and it also tests the subjects at the recognition level (see Table 4).

Table (4) sums up the results as follows:

- The total number and the percentage of the correct responses are $(1240,41.33)$, respectively (See appendix 5).

- The total number and the percentage of the incorrect responses (including avoided items) are (1760, 58.67), respectively (See appendix 5).

- Based on the results obtained from Q1 and Q2, the researchers conclude that the subjects are unaware in identifying the Mphchs and this is obvious from the high number of their incorrect responses $(2001,1760)$ see tables (3) \& (4).

\section{Conclusions}

This section summarizes a number of conclusions based on the general findings of the present study. This section also ends with a set of pedagogical recommendations and suggestions for future studies related to the subject under discussion. In the light of the preceding survey and the discussion related to the findings, and aims of this study, the following conclusions have been drawn:

1) Iraqi EFL university learners at $4^{\text {th }}$ grade are unaware in recognizing and producing (pronouncing) the Mphchs. This is indicated by their low performance in the main test as the rate of their correct responses $(33.3,41.33)$ which is lower significantly than that of their incorrect ones $(66.7,58.67)$.

2) At the production level, the findings of data analysis for question one show the subjects' incompetence to produce, i.e., unable to pronounce the word after adding certain suffixes 
given within the question. The rate of their incorrect responses (concerning Question 1) is (66.7); whereas that of their correct ones is (33.3).

3) The subjects' performance in the whole test has also revealed that EFL university learners' unawareness at the production level exceeds that of the recognition one. The subjects' performance at the production level has obtained a mean of (66.7) against a mean of (58.67) at the recognition level.

\section{Pedagogical Recommendations}

On the bases of the results of the present study, the following pedagogical recommendations can be posited:

1) The process of Mphchs should be determined in the EFL teaching programme. This subject can be introduced in the early years of the teaching programme. In essence, this topic should be taught more extensively at university level extending from first year of study on wards. Moreover, more emphasis and practice on the pronunciation of Mphchs should be exposed to the students in different stages.

2) The reason behind the students' unfamiliarity with Mphchs is that the material of this topic is presented to the students only once during their second stage, and only in one textbook which is limited to some kinds of Mphchs. So, this area of study should be recycled continuously as declared in Al-Hamash and Younis (1985, p. 45) that "second language material should be presented once only. The topics should re-appear again and again in different context, but with increasing depth".

3) The result of the present study can be of use to teachers and syllabus designers since they can provide the necessary information for the preparation of material of teaching programme that can enhance the students to encounter the difficulties in Mphchs.

4) Raise the students' attention to the morphophonemic changes and how the pronunciation of the word is changed after adding a suffix, and this can be achieved by giving the students extensive training or exercises in this regard by listening to native speakers pronouncing morphophonemic changed words.

\section{Suggestions for Further Studies}

The following topics are suggested for further research:

1) A similar study can be conducted for investigating the difficulties encountered by EFL university learners in learning other processes relating to Mphchs.

2) A study can be conducted to show errors made by Iraqi EFL university learners in Mphchs.

3) A contrastive study can be dedicated to show the Mphch in Arabic and English.

\section{Acknowledgements}

We would like to thank College of Education in the University of Wasit for their kind cooperation to conduct this study on the $4^{\text {th }}$ grade college students at the English department during the academic year (2016-2017). Words of thanks are given to the jury members who help us do this study. 
Appendices

\section{Appendix A: Question 1}

Q1/ Transcribe the following words before and after addition in the table below:

\begin{tabular}{|c|c|c|c|c|}
\hline $\begin{array}{l}\text { Item } \\
\text { no }\end{array}$ & $\begin{array}{l}\text { Before or without a } \\
\text { suffix }\end{array}$ & Transcription & $\begin{array}{l}\text { After suffix or with the } \\
\text { suffix }\end{array}$ & Transcription \\
\hline 1 & describe & I & Describe +tion & I \\
\hline 2 & Destroy & I & destroy +tion & I \\
\hline 3 & Divide & I & divide +sion & I \\
\hline 4 & Drive & I & drive+ed & / \\
\hline 5 & Sign & I & sign + al & 1 \\
\hline 6 & House & 1 & house+s & 1 \\
\hline 7 & Cloth & I & cloth+es & I \\
\hline 8 & Advertise & l & advertise+ment & I \\
\hline 9 & Wise & I & Wise+dom & 1 \\
\hline 10 & Negate & I & Negate +ve & I \\
\hline 11 & Oblige & I & oblige +atory & / \\
\hline 12 & Narrate & I & narrate+ive & / \\
\hline 13 & Practice & I & practice+able & 1 \\
\hline 14 & Transit & I & transit+tion & I \\
\hline 15 & Intervene & I & intervene+tion & I \\
\hline 16 & Pateriot & I & pateriot+ic & 1 \\
\hline 17 & Symbole & I & symbole+ism & I \\
\hline 18 & Meter & I & Metr+ic & I \\
\hline 19 & South & I & south+ern & I \\
\hline 20 & Pronounce & I & pronounce+tion & I \\
\hline 21 & electric & I & electric + ian & I \\
\hline 22 & Office & I & office+ial & I \\
\hline 23 & Type & 1 & type+cal & I \\
\hline 24 & Plagiarize & I & plagiarize+ism & I \\
\hline 25 & Phone & I & phone $+\mathrm{ic}$ & I \\
\hline
\end{tabular}

\section{Appendix B: Question 2}

Q2/ Write the number of the item and the correct pronunciation (sounds) for each of the underlined letters:

1-historical (I, $\partial, 0:, æ)$

2-operative (e, air, ei, $\partial$ )

3-christianity (t, $\left.\int, 3, \mathfrak{t}\right)$

4-information (o, e, o:, $\partial)$ 
5-national (ei, ai, æ, $\partial$ )

6-confession (s, z, 3, J)

7-defection (e, æ, I, i :)

8-linear (I, i:, ei , ai)

9-resignation (ei, i:, e , ai )

10-comedian (e, I, i:, $\partial$ )

11-conversation (o, o:, $\mho, \partial$ )

12-dramatic ( $\partial$, æ, a:, e )

13-opposition (o, ov, $\partial v, \partial$ )

14-âbility (ei , æ, e , $\partial$ )

15-advantageous (e, a:, ei , æ )

16-leaden (i:, e , I , $\partial$ )

17-allegation (e, I, i:, $\partial$ )

18-outhority (o:, o , $\partial, æ$ )

19-collegiate (e, i: , I , $\partial$ )

20-combination (ai, ea., i: , I )

21-deputize ( $\partial,, \mho:, \mho$, j $:$ )

22-designate (I, e, i:, $\partial$ )

23-divinity (I, i:, ai , ei )

24-extremity (i:, e , I , $\partial$ )

25-synonymous (o, o:, $\partial$, I ) 


\section{Appendix C: A Draft Copy of the Test}

\section{University of Wasit/ College of Education/ Department of English}

\section{Dear Mr. / Madam}

The researchers intend to conduct an empirical study entitled "Iraqi EFL Students' Awareness of the Pronunciation of Morphophonemic Changed words at a College Level".

The aim of the study is to investigate the performance of Iraqi EFL Fourth Year learners of the Department of English/ College of Education/ University of Wasit in recognizing and pronouncing morphophonemic changes, i.e., the changes in the pronunciation of the basic words after adding certain suffixes. The test consists of (50) items falling into two questions. The first question is devoted to testing the learners at the recognition level and the second question is designed to testing them at the production level.

You are kindly requested to check the written test items and state if they are suitable for this study or not. Any addition or modification will be highly regarded. Your cooperation in this matter which aims at developing teaching English in Iraq will be greatly appreciated. Thank you in advance for your kind cooperation.

\section{The Researchers}

\section{Appendix D: Jury Members}

1) Asst. Prof. Adil Abid Salih, English Language Department, College of Education, Wasit University (Ph.D).

2) Asst. Prof. Ali Muhsin Gharab, English Language Department, College of Education, Wasit University, (Ph.D).

3) Asst. Prof. Fida'a Muhsin Mutar, Oriental Studies Department, College of Art, Wasit University, (Ph.D).

4) Asst. Prof. Enas Naji Kadhim, English Language Department, College of Education, Wasit University, (Ph.D).

5) Asst. Prof. Wa'el Taqi Abid Al-Hadi, English Language Department, College of Education, Wasit University, (Ph.D).

6) Asst. Prof. Mazin Jasim Muhammed, English Language Department, College of Education, Wasit University, (M.A.).

\section{Appendix E: The Formula of Accounting the Total Number and the Percentage of the Correct and Incorrect Responses}

1- Total Number of CRs=the accounting of the students who answer the question correctly.

2-Total Number of IRs= the accounting of the students who answer the question incorrectly.

3-The percentage of CRs $=$ total number of correct responses

Number of items x number of students

The percentage of IRs $=$ total number of incorrect responses

Number of items $x$ number of students 
Tables

\section{Tables}

Table 1: Numbers of Participants before and after Exclusion

\begin{tabular}{|c|c|c|}
\hline $\begin{array}{c}\text { Number of students before } \\
\text { exclusion }\end{array}$ & $\begin{array}{c}\text { Number of participants after } \\
\text { exclusion }\end{array}$ & $\begin{array}{c}\text { Representative } \\
\text { rate }\end{array}$ \\
\hline 156 & 140 & $80 \%$ \\
\hline
\end{tabular}

Table 2: The Facility Value and the Discrimination Power of the Test

\begin{tabular}{|c|c|c|c|c|c|c|c|}
\hline $\begin{array}{l}\text { Question } \\
\text { No. }\end{array}$ & No. of items & FV. & DP. & $\begin{array}{l}\text { Question } \\
\text { No. }\end{array}$ & No. of Items & FV. & DP. \\
\hline \multirow{25}{*}{$\mathbf{Q}^{(1)}$} & \begin{tabular}{|l|}
1 \\
\end{tabular} & 0.23 & 0.48 & \multirow{25}{*}{$\mathbf{Q}^{(2)}$} & 1 & 0.43 & 0.75 \\
\hline & 2 & 0.59 & 0.54 & & 2 & 0.28 & 0.77 \\
\hline & 3 & 0.34 & 0.66 & & 3 & 0.77 & 0.65 \\
\hline & 4 & 0.76 & 0.29 & & 4 & 0.54 & 0.60 \\
\hline & 5 & 0.55 & 0.63 & & 5 & 0.32 & 0.36 \\
\hline & 6 & 0.30 & 0.80 & & 6 & 0.69 & 0.76 \\
\hline & 7 & 0.53 & 0.65 & & 7 & 0.50 & 0.86 \\
\hline & 8 & 0.43 & 0.35 & & 8 & 0.78 & 0.53 \\
\hline & 9 & 0.40 & 0.61 & & 9 & 0.56 & 0.43 \\
\hline & 10 & 0.45 & 0.74 & & 10 & 0.54 & 0.44 \\
\hline & 11 & 0.25 & 0.65 & & 11 & 0.44 & 0.75 \\
\hline & 12 & 0.31 & 0.53 & & 12 & 0.35 & 0.43 \\
\hline & 13 & 0.52 & 0.36 & & 13 & 0.60 & 0.67 \\
\hline & 14 & 0.49 & 0.38 & & 14 & 0.54 & 0.25 \\
\hline & 15 & 0.76 & 0.40 & & 15 & 0.78 & 0.58 \\
\hline & 16 & 0.35 & 0.27 & & 16 & 0.63 & 0.73 \\
\hline & 17 & 0.40 & 0.53 & & 17 & 0.31 & 0.32 \\
\hline & 18 & 0.62 & 0.26 & & 18 & 0.75 & 0.77 \\
\hline & 19 & 0.24 & 0.23 & & 19 & 0.55 & 0.43 \\
\hline & 20 & 0.35 & 0.48 & & 20 & 0.64 & 0.38 \\
\hline & 21 & 0.61 & 0.43 & & 21 & 0.53 & 0.63 \\
\hline & 22 & 0.63 & 0.23 & & 22 & 0.21 & 0.28 \\
\hline & 23 & 0.68 & 0.63 & & 23 & 0.65 & 0.34 \\
\hline & 24 & 0.34 & 0.66 & & 24 & 0.34 & 0.74 \\
\hline & 25 & 0.73 & 0.53 & & 25 & 0.30 & 0.45 \\
\hline
\end{tabular}

Table 3: Frequency and Percentage of the Subjects' Performance at the Production Level in Question 1

\begin{tabular}{|c|c|c|c|c|c|c|c|c|c|}
\hline $\begin{array}{l}\text { No. } \\
\text { of } \\
\text { item } \\
\text { s }\end{array}$ & $\begin{array}{l}\text { No of } \\
\text { correc } \\
t \\
\text { answe } \\
\mathbf{r}\end{array}$ & $\begin{array}{l}\text { Percen } \\
t\end{array}$ & $\begin{array}{l}\text { No. of } \\
\text { incorrec } \\
\mathbf{t} \\
\text { answers }\end{array}$ & $\begin{array}{l}\text { Percen } \\
\mathbf{t}\end{array}$ & $\begin{array}{l}\text { No. } \\
\text { of } \\
\text { item } \\
\text { s }\end{array}$ & $\begin{array}{l}\text { No of } \\
\text { correc } \\
t \\
\text { answe } \\
r\end{array}$ & $\begin{array}{l}\text { Percen } \\
t\end{array}$ & $\begin{array}{l}\text { No. of } \\
\text { incorrec } \\
t \\
\text { answers }\end{array}$ & $\begin{array}{l}\text { Percen } \\
\mathbf{t}\end{array}$ \\
\hline 1. & 31 & 26 & 89 & 74 & 14. & 20 & 17 & 100 & 83 \\
\hline 2. & 57 & 47 & 63 & 52 & 15. & 52 & 43 & 68 & 57 \\
\hline
\end{tabular}




\begin{tabular}{|l|l|l|l|l|l|l|l|l|l|}
\hline 3. & 60 & 50 & 60 & 50 & 16. & 22 & 18 & 98 & 81 \\
\hline 4. & 44 & 37 & 76 & 63 & 17. & 67 & 56 & 53 & 44 \\
\hline 5. & 33 & 27 & 87 & 72 & 18. & 55 & 46 & 65 & 54 \\
\hline 6. & 62 & 51 & 58 & 48 & 19. & 40 & 33 & 80 & 67 \\
\hline 7. & 13 & 11 & 107 & 89 & 20. & 56 & 47 & 64 & 53 \\
\hline 8. & 25 & 21 & 95 & 79 & 21. & 24 & 20 & 96 & 80 \\
\hline 9. & 36 & 30 & 84 & 70 & 22. & 32 & 27 & 88 & 73 \\
\hline 10. & 49 & 41 & 71 & 59 & 23. & 45 & 37 & 75 & 62 \\
\hline 11. & 53 & 44 & 67 & 56 & 24. & 37 & 31 & 83 & 69 \\
\hline 12. & 23 & 19 & 97 & 81 & 25. & 21 & 17 & 99 & 82 \\
\hline 13 & 42 & 35 & 78 & 65 & Total & 999 & 33.3 & 2001 & 66.7 \\
\hline
\end{tabular}

Table 4: Frequency and Percentage of the Subjects' Performance at the Recognition level in

Question 2

\begin{tabular}{|l|l|l|l|l|l|l|l|l|l|}
\hline $\begin{array}{l}\text { No. } \\
\text { of } \\
\text { Item } \\
\text { s }\end{array}$ & $\begin{array}{l}\text { No. of } \\
\text { correct } \\
\text { respons } \\
\text { es }\end{array}$ & $\begin{array}{l}\text { Perce } \\
\text { nt }\end{array}$ & $\begin{array}{l}\text { No. of } \\
\text { incorrec } \\
\text { t } \\
\text { respons } \\
\text { es }\end{array}$ & $\begin{array}{l}\text { Perce } \\
\text { nt }\end{array}$ & $\begin{array}{l}\text { No. } \\
\text { of } \\
\text { Item } \\
\text { s }\end{array}$ & $\begin{array}{l}\text { No. of } \\
\text { correct } \\
\text { respons } \\
\text { es }\end{array}$ & $\begin{array}{l}\text { Perce } \\
\text { nt }\end{array}$ & $\begin{array}{l}\text { No. of } \\
\text { incorrec } \\
\text { t } \\
\text { respons } \\
\text { es }\end{array}$ & $\begin{array}{l}\text { Perce } \\
\text { nt }\end{array}$ \\
\hline 1. & 70 & 58 & 50 & 42 & 14. & 63 & 52 & 57 & 47 \\
\hline 2. & 63 & 52 & 57 & 47 & 15. & 41 & 34 & 79 & 66 \\
\hline 3. & 56 & 47 & 64 & 53 & 16. & 35 & 59 & 85 & 71 \\
\hline 4. & 60 & 50 & 60 & 50 & 17. & 27 & 22 & 93 & 77 \\
\hline 5. & 44 & 37 & 76 & 63 & 18. & 57 & 47 & 63 & 52 \\
\hline 6. & 50 & 42 & 70 & 58 & 19. & 20 & 17 & 100 & 83 \\
\hline 7. & 33 & 27 & 87 & 72 & 20. & 74 & 61 & 46 & 38 \\
\hline 8. & 66 & 55 & 54 & 45 & 21. & 59 & 49 & 61 & 51 \\
\hline 9. & 36 & 30 & 84 & 70 & 22. & 45 & 37 & 75 & 62 \\
\hline 10. & 55 & 46 & 65 & 54 & 23. & 37 & 31 & 83 & 69 \\
\hline 11. & 40 & 33 & 80 & 67 & 24. & 54 & 45 & 66 & 55 \\
\hline 12. & 43 & 36 & 77 & 64 & 25. & 59 & 49 & 61 & 51 \\
\hline 13. & 53 & 44 & 67 & 56 & Tota & 1240 & 41.33 & 1760 & 58.67 \\
\hline
\end{tabular}

\section{References}

[1] Ahman, J. S. and Glock, M. D. (1975). Measuring and evaluating education achievement $.5^{\text {th }}$. ed. Boston: Allen and Bocon.

[2] Alderson, J. C., Clapham, C. and Wall, D. (1995). Language constructions and evaluation. Cambridge: Cambridge University Press.

[3] Al-Hamash, Kh. and Younis, H. (1985). Principles and techniques of teaching English as a second language. Baghdad: al-Rusafa

[4] Bachman, L.F. 1990. Fundamentals consideration in language testing. New York: Oxford University Press.

[5] Baker, C. (1989). Language testing: A critical survey. London: Edward. 
[6] Bell, R. T. (1981). An introduction to applied linguistics: Approaches in and methods Language Teaching. London: Bats ford.

[7] Bloom, B. S., Madaus, G. F. and Hastings, T. J. (1981). Evaluation to improve learning. New York: Harcourt, Bace and World.

[8] Brown, J. D. (1987). Principles of language learning and teaching. $3^{\text {rd }}$ Ed. New Jersey: Prentice Hall, Inc.

[9] Brown, J. D. (1996). Testing in language programmes. Englewood Cliffs: Prentice Hall, Inc.

[10] Davies, A. (1999). An introduction to applied linguistics: From practice to theory. Edinburgh: Edinburgh University Press.

[11] Ebel, R. (1972). Essential of educational measurement. Englewood Cliffs, New Jersey: Prentice Hall.

[12] Ferguson, G. A. (1966). Statistical analysis in psychology and education. New York: McGrow Hall.

[13] Fudge, E. (1973). Phonology. England: Penguin Books Ltd.

[14] Gronlund, N. E. (1976). Measurement and evaluation testing $.3^{\text {rd }}$.ed. New York: Macmillan Publishing Co. Inc.

[15] Harris, D. P. (1969). Testing english as a second language. New York: McGrow-Hall.

[16] Harrison, A. (1993). A language testing handbook. London: Longman.

[17] Heaton, J. B. (1988). Writing English language test. London: Longman.

[18] Khodadady, E. (1999). Multiple choice items in testing: Practice and theory. Tehran: Rahnama Publication.

[19] Kroeger, P. R. (2005). Analyzing grammar: An introduction. New York: Cambridge University Press.

[20] Larson, H. J. (1982). Introduction to probability theory and statistical inference. $3^{\text {rd }}$ Ed. New York: John Willey and Sons, Inc.

[21] Lass, R. (1998). Phonology. Cambridge: CUP.

[22] Roberts, P. (1967). Modern grammar. London: Harcourt, Brace World.

[23] Stageberg, N. (1981). An introductory English grammar. New York: Holt, Rinnhartand Wiston, Inc.

[24] Stiggins, R. J. (1999). Evaluating classroom assessment training in teacher educational programme. Educational Measurement: Issues and Practice, 18(1), 23-27.

[25] Thakur, D. (1997). Linguistics simplified morphology. New York: B.B.

[26] Thakur, D. (1999). Linguistics simplified semantics. New York: B.B.

[27] Van Els, T. (1984). Applied linguistics and learning and teaching of foreign language. London: Edward Arnold Publisher, Ltd.

[28] Weeren, J. van and Theunissen, T.J.J.M. (1987). Testing pronunciation: An application of generalizability theory", Language Learning 37, 1: 109-22.

[29] Weir, C. (1993). Understanding and developing language test. London: Prentice - Hall, Ltd.

\footnotetext{
*Corresponding author.

E-mail address: alhili.usm @gmail.com
} 